\title{
Psychometric evaluation and refinement of the Pain Response Preference Questionnaire
}

\author{
Lachlan A McWilliams $\mathrm{PhD}^{1}$, John Kowal $\mathrm{PhD}^{2}$, Donald Sharpe $\mathrm{PhD}^{3}$, Bruce D Dick PhD ${ }^{4}$
}

LA McWilliams, J Kowal, D Sharpe, BD Dick. Psychometric evaluation and refinement of the Pain Response Preference Questionnaire. Pain Res Manag 2014;19(1):42-48.

BACKGROUND: The Pain Response Preference Questionnaire (PRPQ) assesses preferences regarding pain-related social support. The initial factor analytical study of the PRPQ produced four empirically supported scales labelled Solicitude, Management, Encouragement and Suppression. A second study produced similar findings, but suggested that the Management and Encouragement scales be combined into a single scale labelled Activity Direction.

OBJECTIVES: To use factor analytical methods to evaluate these competing configurations of the PRPQ (ie, three versus four scales) and to further refine the measure. The ability of the PRPQ scales to account for pain severity and disability ratings was also evaluated.

METHODS: Chronic pain patients $(n=201)$ completed the PRPQ along with the Pain Catastrophizing Scale (PCS) and self-reports of pain severity and disability.

RESULTS: Confirmatory factor analysis indicated that both models tested provided a poor fit to the data. A follow-up exploratory factor analysis was used to further refine the PRPQ scales and resulted in scales labelled Solicitude, Encouragement and Suppression. Supportive of the potential clinical utility of the PRPQ, Suppression was positively associated with pain severity and Solicitude was positively associated with disability. These two scales were also positively associated with the PCS. Supportive of the incremental validity of the PRPQ, a multiple regression analysis indicated that the Solicitude scale accounted for unique variance in disability ratings beyond that accounted for by demographic/clinical variables and the PCS.

CONCLUSIONS: The PRPQ has promise as a clinical assessment measure and for advancing research examining the interpersonal context of pain.

Key Words: Catastrophizing; Communal coping; Encouragement; Social support; Solicitous support; Suppression

Cordyce's (1) operant conditioning model of chronic pain posits that Fignificant others' responses to pain behaviour play a key role in chronic pain and disability. Consistent with this model, solicitous responses have been found to be associated with increased pain behaviour (2) and poorer functional outcomes $(3,4)$. Two recent developments have challenged Fordyce's model. First, a qualitative study by Newton-John and Williams (5) investigating spousal responses to pain behaviour and chronic pain patients' preferences regarding such responses revealed that forms of support typically classified as solicitous were rated relatively unfavourably by patients, and responses encouraging active coping received the most favourable ratings from patients. This pattern of findings raises the possibility that behaviours conceptualized as solicitous in past studies may not be positive reinforcers for all individuals with chronic pain. Second, it has been proposed that pain behaviour can be considered to be a form of emotional disclosure (6). From this perspective, supportive responses to pain

\section{L'évaluation psychométrique et l'amélioration du questionnaire sur les préférences de réponses à la douleur}

HISTORIQUE : Le questionnaire PRPQ sur les préférences de réponses à la douleur évalue les préférences à l'égard des soutiens sociaux liés à la douleur. L'étude analytique initiale des facteurs du PRPQ a produit quatre échelles empiriques nommées sollicitude, gestion, encouragement et suppression. Une deuxième étude a donné des résultats similaires, mais indiquait que les échelles de gestion et d'encouragement peuvent être combinées en une seule, nommée orientation de l'activité.

OBJECTIFS : Utiliser une méthodologie analytique des facteurs pour évaluer ces configurations concurrentes du PRPQ (soit trois ou quatre échelles) et améliorer la mesure. Les chercheurs ont également évalué la capacité des échelles du PRPQ à tenir compte du classement de la gravité de la douleur et de l'incapacité.

MÉTHODOLOGIE : Des patients souffrant de douleur chronique ( $\mathrm{n}=201)$ ont rempli le PRPQ et l'échelle de catastrophisation de la douleur (ÉCD) et des autodéclarations de la gravité de la douleur et de l'incapacité.

RÉSULTATS : Une analyse de confirmation des facteurs a indiqué que les deux modèles étaient mal adaptés aux données. Une analyse exploratoire de suivi des facteurs a permis d'améliorer les échelles du PRPQ et de produire des échelles nommées sollicitude, encouragement et suppression. En appui avec l'utilité clinique potentielle du PRPQ, l'échelle suppression s'associait positivement à la gravité de la douleur et l'échelle sollicitude, à l'incapacité. Ces deux échelles s'associaient également positivement à l'ÉCD. En appui avec la valeur incrémentielle du PRPQ, une analyse de régression multiple indiquait que l'échelle sollicitude tenait compte de la variance unique des plages d'incapacités au-delà de celle transmise par les variables démographiques et cliniques et par l'ÉCD.

CONCLUSIONS : Le PRPQ est prometteur comme mesure d'évaluation clinique et pour l'avancement de la recherche sur le contexte interpersonnel de la douleur.

behaviour, particularly those that are emotionally validating, may have desirable outcomes for the individual experiencing pain, such as enhancing intimacy and emotional regulation, which have been ignored in operant approaches to chronic pain.

These new perspectives imply that preferences regarding painrelated support are important. A measure of such preferences has the potential to inform behavioural and interpersonally focused models of chronic pain by identifying forms of support that are most likely to serve as positive reinforcement or to foster intimacy. To this end, McWilliams et al (7) developed the Pain Response Preference Questionnaire (PRPQ). It assesses the degree to which several types of responses to pain are desired from a significant other. The items for this measure were designed to capture the forms of support identified by Newton-John and Williams (5). The initial psychometric study (7) used a large student sample. An exploratory factor analysis of the items produced four empirically derived scales labelled Solicitude,

\footnotetext{
${ }^{1}$ Department of Psychology, University of Saskatchewan, Saskatoon, Saskatchewan; ${ }^{2}$ Department of Psychology, The Ottawa Hospital Rehabilitation Centre, Ottawa, Ontario; ${ }^{3}$ Department of Psychology, University of Regina, Regina, Saskatchewan; ${ }^{4}$ Department of Anesthesiology and Pain Medicine, University of Alberta, Edmonton, Alberta

Correspondence: Dr Lachlan A McWilliams, Department of Psychology, University of Saskatchewan, 9 Campus Drive, 154 Arts, Saskatoon, Saskatchewan S7N 5A5. Telephone 306-966-6966, fax 306-966-6630, e-mail lachlan.mcwilliams@usask.ca
} 
Management, Encouragement and Suppression. Relationships among these scales and theoretically related measures supported their construct validity. For example, the Use of Emotional Social Support scale of the COPE had a strong positive association with the Solicitude scale and a negative association with the Suppression scale.

To further develop the PRPQ, McWilliams et al (8) examined its psychometric properties using data from a sample of chronic pain patients attending a multidisciplinary pain clinic. Their exploratory factor analysis produced results similar to those of the earlier factor analytical study (7). However, it indicated that the Management and Encouragement scales were best combined into a single scale labelled Activity Direction. McWilliams et al (8) also examined relationships between the PRPQ scales and disability ratings. Individuals with a strong desire for solicitous support would be expected to have their pain behaviour highly reinforced by such support. As a result, they may experience higher levels of disability than those with lower levels of interest in solicitous support. Alternatively, individuals with a strong desire for solicitous support may engage in pain behaviour as a method of eliciting such support, and this method of support seeking could result in elevated levels of disability. Inconsistent with these suggestions, the correlation between the Solicitude scale and disability ratings was small and not statistically significant. However, the regression model that adjusted for sex, pain severity and the other PRPQ scales revealed that Solicitude was positively associated with disability. Also of importance, this model indicated that Activity Direction and Suppression were both negatively associated with disability.

The present study used factor analytical methods to evaluate the appropriateness of the competing configurations of the PRPQ (ie, three versus four scales) in an additional chronic pain patient sample and to further refine the measure. The second objective was to determine whether previous findings of associations between the PRPQ scales and disability ratings could be replicated. The final objective was to investigate the incremental validity of the PRPQ. To this end, the ability of the PRPQ scales to account for variance in pain severity and disability beyond that accounted for by the Pain Catastrophizing Scale (PCS) (9) was evaluated. Pain catastrophizing is one of the most consistent psychological predictors of pain-related outcomes, with hundreds of studies reporting positive associations between self-reports of catastrophizing and negative pain-related outcomes such as pain intensity, psychological distress and disability (10). Thus, a measure of pain catastrophizing, such as the PCS, is well suited for evaluating the incremental validity of any new pain-related measure because it would be expected to be associated with a wide range of criterion variables and to account for a relatively large amount of variance in such variables. As well, the PCS is widely used in clinical settings; therefore, demonstrating that the PRPQ assesses clinically relevant information not already captured by the PCS would be particularly helpful for clinicians evaluating the potential utility of the PRPQ.

\section{Participants and procedure}

\section{METHODS}

Participants were consecutive patients admitted to a tertiary care outpatient, group-based, interdisciplinary chronic pain management program at the Ottawa Hospital Rehabilitation Centre (Ottawa, Ontario). The data used in the present study were collected as part of the initial screening of patients and during their clinical assessments once admitted to the treatment program. All study participants provided written informed consent for their data to be used for research purposes. The present study was approved by the Research Ethics Board of the Ottawa Hospital.

The main inclusion criteria for the program and study were the ability to speak and write in English or French, and medical, psychological and physical appropriateness. Patients were excluded if they were medically unstable, had a primary substance abuse problem or were actively seeking a cure for their pain symptoms. Those with pain limited to headaches, gynecological/urinary issues, pelvic pain or gastrointestinal issues were also excluded.
Two hundred fifty-seven patients were eligible for inclusion in the present study. The data from six patients were not included because these individuals reported difficulty completing the study measures. Given that the factor analytical methods used required responses to the entire PRPQ for each participant, data from 50 participants who did not complete the entire PRPQ were not included in the present analyses. The majority of these cases $(66.0 \%)$ were dropped because of missing data on only one PRPQ item. Those excluded from the present study due to missing PRPQ data $(n=50)$ did not differ from those included on any of the other study variables (ie, catastrophizing, pain severity, disability, pain duration, age and sex). The final sample consisted of 201 patients. Participants were primarily female (63.2\%), Caucasian $(86.0 \%)$, and married or in a common-law relationship (66.5\%). In terms of pain location/type, the most commonly reported categories were low back pain $(30.5 \%)$, pain at three or more sites (20.4\%), all-over pain (10.9\%) and neck pain (8.5\%).

\section{Self-report measures}

Patients' sociodemographic characteristics (eg, age, sex and ethnic background) and clinical information (eg, pain duration and location) were collected using a standardized patient history questionnaire administered as part of the patient screening process. The following self-report measures were completed on admission to the treatment program.

PRPQ: The PRPQ is a 39-item measure of pain-related social support preferences $(7,8)$. It presents a wide range of ways that one's partner or spouse could respond to one's pain (eg, "When I am in pain, I want my significant other to help me with whatever I am doing"). Respondents indicate how they would like their partner to respond to them, rather than how partners actually respond. Those not married or in a romantic relationship were asked to indicate how they would like others close to them (eg, friends and family) to respond. Each item is rated on a four-point Likert scale ranging from 1 (strongly disagree) to 4 (strongly agree), and scores for the scales are created by calculating the mean score of the items comprising each scale. As noted earlier, previous studies have supported two slightly different sets of scales $(7,8)$.

PCS: The PCS (9) consists of 13 items assessing how frequently individuals experience catastrophic thoughts and feelings during pain episodes, with responses ranging from 0 (not at all) to 4 (all the time). The PCS yields a total score ranging from 0 to 52 , with higher scores representing greater pain catastrophizing. The PCS has shown strong internal consistency and test-retest reliability, and good construct validity (9). In the present study, this scale had an excellent level of internal consistency (Cronbach's alpha $=0.93$ ).

Pain severity: Pain severity was assessed using four items asking participants to rate their current pain, as well as their worst, least and average pain over the course of the past two weeks. Participants rated each item using an 11-point numerical rating scale (11) ranging from 0 (no pain) to 10 (as intense as you can imagine). A composite and internally consistent (Cronbach's alpha $=0.85$ ) index of pain severity was created by averaging scores on these four pain severity rating scales.

Disability: Disability was assessed using a scale recommended by the Task Force on Records and Data Retrieval of the International Association for the Study of Pain (12). Respondents reported on the degree to which they have difficulty performing 16 activities of daily living (eg, making meals, getting in and out of bed, participating in social activities). The items are rated on a five-point scale anchored by 1 (no difficulty) and 5 (unable to do). Total scores range from 16 to 80 , with higher scores indicating greater functional limitations. In the present study, this measure had excellent internal consistency (Cronbach's alpha $=0.92$ ).

\section{RESULTS}

\section{Confirmatory factor analysis}

As a preliminary step, the normality of the PRPQ data was examined. Mardia's coefficient of multivariate kurtosis was 164.23 (critical 
ratio $=31.68)$ and is indicative of non-normality. However, when examining data from the individual items, only six items produced critical ratios greater than \pm 3 , and none produced critical ratios greater than \pm 5 . These absolute values of critical ratios are all lower than the range (ie, 10 to 20) identified by Kline (13) as problematic. It is also important to note that parameter estimates and most model fit indexes have been found to be robust to non-normality when using maximum-likelihood estimation and samples sizes $\geq 100$ (14). Based on these guidelines and the current sample size, confirmatory factor analysis with maximum-likelihood estimation was appropriate.

AMOS 18 (IBM Corporation, USA) was used to test two competing models. The first examined the three-factor model recently found in a chronic pain patient sample (8). To select the most promising items, the model tested included only the 25 items selected in that study to create scales labelled Solicitude (10 items), Activity Direction (10 items) and Suppression (five items). The second model tested was based on the initial four-factor solution obtained using data from a student sample (7). The Solicitude and Suppression items and factors were consistent between the two models. The difference between the two models was that, in the second model, the Activity Direction factor was separated into an Encouragement factor (six items) and a Management factor (four items).

To evaluate each model, the following statistics were examined. A statistically significant $\chi^{2}$ likelihood ratio suggests that observed covariance between the items remains unexplained, while statistical nonsignificance implies a good fit to the data (15). Given the sensitivity of this statistic to sample size, several other frequently used indexes of model fit were used to evaluate the models. These were the goodness-offit index (GFI) (16), the comparative fit index (CFI) (17) and the root mean square error of approximation (RMSEA) (18). Values of GFI and CFI $>0.90$ (liberal criteria) or $>0.95$ (conservative criteria), and values of RMSEA $<0.08$ (liberal criteria) or $<0.05$ (conservative criteria) are suggestive of good fit. The Akaike Information Criterion (AIC) was also used to compare models, with a smaller AIC value indicating a better fitting model (19).

Examination of the parameter estimates for both models indicated that all items were strongly associated with their respective factors (except those constrained to 1 for identification purposes) at $\mathrm{P}<0.005$. The $\chi^{2}$ values were statistically significant for the three-factor model $\left(\chi^{2} \quad[272, \mathrm{n}=201]=606.66 ; \mathrm{P}<0.001\right)$ and the four-factor model $\left(\chi^{2}[269, \mathrm{n}=201]=562.79 ; \mathrm{P}<0.001\right)$. For the three-factor model, the fit indexes were $\mathrm{GFI}=0.80, \mathrm{CFI}=0.79$, RMSEA $=0.08$ (90\% CI 0.07 to 0.09 ) and $\mathrm{AIC}=712.66$. For the four-factor model, the fit indexes were $\mathrm{GFI}=0.82, \mathrm{CFI}=0.82, \mathrm{RMSEA}=0.07(90 \% \mathrm{CI} 0.07$ to 0.08$)$ and $\mathrm{AIC}=674.79$. These values suggest that while the four-factor model was somewhat better than the three-factor model, neither model adequately accounted for the covariances between the PRPQ items. Examination of modification indexes suggested correlating the error terms of two of the items of the Suppression factor, but the resulting improvement in model fit would be modest. Floyd and Widaman (20) noted that factor structures are difficult to confirm when testing models based on data from even moderately lengthy questionnaires. Questionnaires with many items per scale tend to have high levels of internal consistency and also tend to produce robust exploratory factor analytical solutions. However, lengthy scales generally include items that will have correlated errors, making it unlikely that factor models based on these scales will be found to be satisfactory using confirmatory factor analysis. Given these observations and the number of items in the PRPQ scale, the current confirmatory factor analytical findings were not surprising.

\section{Exploratory factor analysis}

To provide additional item-level data to inform further refinement of the PRPQ, SPSS version 15 (IBM Corporation, USA) was used to conduct an exploratory factor analysis of the PRPQ. This was conducted with the 25 items used in the earlier confirmatory factor analysis. The factor analytical methods used were identical to those used in the two earlier studies of the PRPQ $(7,8)$; specifically, principal axis analysis, promax rotation and the use of parallel analysis to determine the number of factors to retain.

Parallel analysis suggested that a three-factor solution would be appropriate. A forced three-factor solution accounted for $45.96 \%$ of the variance. The pattern matrix for this solution is presented in Table 1 . Loadings of $\geq 0.32$ were considered to be salient for the purpose of interpreting the factors (21). There was one complex item (ie, an item with a salient loading on two or more factors). To facilitate comparisons between the present findings and those of the earlier studies, Table 1 also indicates the factor on which each item had its most salient loading in the earlier studies.

Factor 1 included 11 salient items and accounted for $25.71 \%$ of the variance. All but one of the items with salient loadings on this factor were used in the Solicitude scales of previous studies, so this factor was labelled Solicitude. The one exception to this pattern was an item from the original Management scale, which had the lowest salient loading on this factor.

Factor 2 included nine items and accounted for $12.96 \%$ of the variance. This factor was comprised of items that were included in the original Encouragement and Management scales (7). In terms of the most recent set of PRPQ scales (8), all of the items loading on this factor were part of the Activity Direction scale. Thus, this factor was labelled Activity Direction.

The third factor accounted for $7.29 \%$ of the variance. This factor was comprised of five items, all of which had been included in the Suppression scales used in earlier studies. Based on this pattern of loadings, this factor was labelled Suppression.

\section{PRPQ scale refinement}

The current pattern matrix and the findings from the two earlier factor analytical studies of the PRPQ were used to develop a revised set of $\mathrm{PRPQ}$ scales. Items were also dropped if they negatively impacted on a scale's internal consistency. The goal was to create scales that would be most likely to receive empirical support in subsequent studies. The item-to-scale assignments used for these scales are reported in Table 1.

Items were included in the Solicitude scale if they had salient loadings on the Solicitude factor in the current study (with no cross-loadings) and if they had been included in the earlier versions of the Solicitude scale. This procedure resulted in a 10-item Solicitude scale with a high level of internal consistency (Cronbach's alpha $=0.86$ ).

The possibility of creating an Activity Direction scale (ie, a combination of Encouragement and Management) was considered. However, the items with the strongest loadings on the Activity Direction factor were from the original Encouragement scale found by McWilliams et al (7). In contrast, the Management items included in this factor had relatively weak loadings on the factor. Based on these observations, a five-item Encouragement scale was created. This scale had adequate internal consistency (Cronbach's alpha $=0.72$ ).

All of the items on the Suppression factor were from the original six-item Suppression scale (7). The current Suppression scale was created by using items with salient loadings on the factor that did not have a salient cross-loading on another factor. Item 37 met the initial criteria for inclusion, but was dropped from the scale because it negatively impacted the internal consistency of the scale. The resulting three-item scale had a high level of internal consistency (Cronbach's alpha $=0.82$ ).

\section{PRPQ descriptive statistics and intercorrelations}

Descriptive statistics and intercorrelations for the PRPQ scale are reported in Table 2. There was a positive association between the Solicitude and Encouragement scales, as well as a positive association between the Encouragement and Suppression scales. Based on Cohen's criteria (22) for characterizing correlations as effect sizes, these associations would be considered to be small (ie, 0.10 to 0.30 ). The association between the Solicitude and Suppression scales was trivial and statistically nonsignificant. Thus, the overall pattern of correlations indicates that the PRPQ scales measure constructs that are relatively 


\begin{tabular}{|c|c|c|c|c|c|c|}
\hline \multirow[b]{3}{*}{ Item number and abbreviated content } & \multicolumn{6}{|c|}{ Performance in previous } \\
\hline & \multicolumn{3}{|c|}{ Loadings on current factors } & \multicolumn{2}{|c|}{ studies } & \multirow[b]{2}{*}{ Current study } \\
\hline & 1 & 2 & 3 & 1 & 2 & \\
\hline 7. Offer me help & 0.77 & -0.08 & -0.09 & Solicitude & Solicitude & Solicitude \\
\hline 12. Ask if I need help & 0.73 & -0.08 & 0.00 & Solicitude & Solicitude & Solicitude \\
\hline 31. Help me out & 0.72 & 0.02 & -0.10 & Solicitude & Solicitude & Solicitude \\
\hline 14. Treat me with extra care and concern & 0.72 & -0.16 & 0.11 & Solicitude & Solicitude & Solicitude \\
\hline 23. Say he or she is concerned & 0.68 & -0.07 & 0.16 & Solicitude & Solicitude & Solicitude \\
\hline 6. Do nice things to make me feel better & 0.63 & 0.07 & -0.01 & Solicitude & Solicitude & Solicitude \\
\hline 1. Help me with whatever I am doing & 0.61 & -0.20 & 0.03 & Solicitude & Solicitude & Solicitude \\
\hline 32. Take good care of me & 0.60 & 0.02 & 0.05 & Solicitude & Solicitude & Solicitude \\
\hline 33. Seem interested in my pain & 0.48 & 0.06 & 0.05 & Solicitude & Solicitude & Solicitude \\
\hline 3. Ask me about my pain & 0.39 & 0.19 & -0.03 & Solicitude & Solicitude & Solicitude \\
\hline 8. Distract me from my pain & 0.38 & 0.27 & 0.10 & Management & Activity Direction & Not used \\
\hline 30. Tell me I can do things despite pain & -0.26 & 0.71 & 0.05 & Encouragement & Activity Direction & Encouragement \\
\hline 11. Try to keep me involved in activities & -0.05 & 0.69 & 0.02 & Encouragement & Activity Direction & Encouragement \\
\hline 36. Tell me that I can handle the pain well & -0.04 & 0.62 & 0.10 & Encouragement & Activity Direction & Encouragement \\
\hline 18. Try to help me stay positive & 0.07 & 0.60 & -0.22 & Encouragement & Activity Direction & Encouragement \\
\hline 2. Encourage me to keep going & -0.14 & 0.51 & 0.04 & Encouragement & Activity Direction & Encouragement \\
\hline 28. Suggest ways to stop making my pain worse & 0.27 & 0.40 & 0.10 & Management & Activity Direction & Not used \\
\hline 13. Tell me to keep active & 0.09 & 0.39 & 0.26 & Encouragement & Activity Direction & Not used \\
\hline $\begin{array}{l}\text { 34. Suggest fun or interesting activities that will not } \\
\text { make my pain much worse }\end{array}$ & 0.16 & 0.35 & -0.10 & Management & Activity Direction & Not used \\
\hline 16. Offer suggestions about managing the pain & 0.19 & 0.33 & 0.07 & Management & Activity Direction & Not used \\
\hline 15. Change topics when I talk about my pain & 0.13 & 0.05 & 0.86 & Suppression & Suppression & Suppression \\
\hline 10. Stop me from talking about my pain & 0.09 & 0.12 & 0.68 & Suppression & Suppression & Suppression \\
\hline 20. Tell me not to talk about my pain & 0.01 & 0.09 & 0.66 & Suppression & Suppression & Suppression \\
\hline 21. Ignore my pain & -0.42 & -0.14 & 0.47 & Suppression & Suppression & Not used \\
\hline 37. Act like I am not in pain & -0.21 & -0.18 & 0.34 & Suppression & Suppression & Not used \\
\hline
\end{tabular}

Values in bold indicate salient loadings ( $\geq 0.32$ ). Study 1 refers to McWilliams et al (7); study 2 refers to McWilliams et al (8). Factors/scales are Solicitude, Management, Encouragement, Suppression, Activity Direction and Not Used

\section{TABLE 2}

Descriptive statistics and intercorrelations of all variables $(n=201)$

\begin{tabular}{|c|c|c|c|c|c|c|c|c|c|c|}
\hline Measure & Mean \pm SD & 1 & 2 & 3 & 4 & 5 & 6 & 7 & 8 & 9 \\
\hline 1. PRPQ Solicitude & $2.89 \pm 0.51$ & - & $0.28^{* * *}$ & 0.04 & $0.20^{* *}$ & 0.04 & $0.17^{*}$ & -0.08 & -0.05 & $0.25^{* *}$ \\
\hline 2. PRPQ Encouragement & $2.87 \pm 0.53$ & & - & $0.27^{* * *}$ & 0.07 & 0.01 & 0.09 & $-0.17^{*}$ & $-0.17^{*}$ & 0.06 \\
\hline 3. PRPQ Suppression & $2.15 \pm 0.71$ & & & - & $0.20^{* *}$ & $0.15^{\star}$ & 0.10 & -0.13 & 0.02 & -0.13 \\
\hline 4. Pain Catastrophizing Scale & $25.79 \pm 12.02$ & & & & - & $0.27^{\star \star *}$ & $0.35^{\star * *}$ & 0.03 & -0.12 & -0.04 \\
\hline 5. Pain severity ratings & $6.42 \pm 1.40$ & & & & & - & $0.43^{* * *}$ & 0.04 & -0.12 & -0.02 \\
\hline 6. Disability ratings & $42.27 \pm 10.34$ & & & & & & - & 0.11 & 0.01 & -0.06 \\
\hline 7. Pain duration (months) & $82.80 \pm 93.59$ & & & & & & & - & $0.17^{*}$ & -0.11 \\
\hline 8. Age & $47.24 \pm 10.31$ & & & & & & & & - & -0.04 \\
\hline 9. Sex $($ male $=0$, female $=1)$ & - & & & & & & & & & - \\
\hline
\end{tabular}

${ }^{*} P<0.05,{ }^{* *} P<0.01,{ }^{* *} P<0.001 . P R P Q$ Pain Response Preference Questionnaire

distinct from one another (eg, the largest $\mathrm{R}^{2}$ value indicated $7.8 \%$ shared variance between Solicitude and Encouragement).

Associations between the PRPQ scales and the other study measures

Table 2 also reports correlations involving all of the other study measures. All of the clinical (ie, pain severity ratings, disability ratings and pain duration) and demographic (ie, age and sex) variables were associated with at least one PRPQ scale. Of particular relevance to the subsequent regression analyses, the PRPQ Solicitude scale was positively associated with disability ratings and the PRPQ Suppression scale was positively associated with pain severity ratings. The findings regarding the PCS indicated that it was a suitable measure for assessing the incremental validity of the PRPQ scales. It was positively associated with two of the PRPQ scales (Solicitude and Suppression) and with both the criterion variables used in the regression analyses investigating the incremental validity of the PRPQ.

Regression analyses predicting pain and disability

A multiple regression analysis was used to determine whether the association between Suppression and pain severity would remain when adjusting for demographic characteristics and including participants' scores on the other PRPQ scales. To examine the possibility that one type of preference would moderate the relationship between another preference and disability, interaction effects involving the PRPQ scales were also included. Based on the recommendations of Aiken and West (23), the continuous predictor variables were centred and the interaction terms were created with these centred variables. Sex, age and pain duration were entered in step 1. The three PRPQ scales were entered in step 2. Two-way interactions between the PRPQ scales 
TABLE 3

Summary of regression analyses predicting pain severity and disability ratings $(n=201)$

\begin{tabular}{|c|c|c|c|c|c|}
\hline $\begin{array}{l}\text { Dependent } \\
\text { variable }\end{array}$ & Step & Predictors & $\beta$ & $\mathbf{F}$ & $\Delta \mathbf{R}^{2}$ \\
\hline \multirow[t]{6}{*}{ Pain severity } & 1 & Sex & 0.00 & 1.13 & 0.017 \\
\hline & & Age & -0.14 & & \\
\hline & & Pain duration & 0.08 & & \\
\hline & 2 & PRPQ Sol & 0.04 & 1.61 & 0.030 \\
\hline & & PRPQ Enc & -0.07 & & \\
\hline & & PRPQ Sup & $0.18^{*}$ & & \\
\hline \multirow{7}{*}{$\begin{array}{c}\text { Disability } \\
\text { ratings }\end{array}$} & 1 & Sex & -0.08 & $12.17^{\star * *}$ & $0.199^{\star * \star}$ \\
\hline & & Age & 0.06 & & \\
\hline & & Pain severity ratings & $0.43^{* * *}$ & & \\
\hline & & Pain duration & 0.10 & & \\
\hline & 2 & PRPQ Sol & $0.17^{*}$ & $8.53^{* * *}$ & $0.037^{*}$ \\
\hline & & PRPQ Enc & 0.07 & & \\
\hline & & PRPQ Sup & 0.01 & & \\
\hline
\end{tabular}

Sex coded as male $=0$ and female $=1$. Standardized coefficients reported are from the final models. ${ }^{*} P<0.05$; ${ }^{* * *} P<0.001$. Enc Encouragement; $P R P Q$ Pain Response Preference Questionnaire; Sol Solicitude; Sup Suppression

were entered in step 3, and the three-way interaction between the PRPQ scales was entered in step 4. The results are summarized as the first analysis reported in Table 3. Given that steps 3 and 4 failed to improve the model and revealed no additional statistically significant findings, these steps are not reported in Table 3. The models based on steps 1 and 2 were both not statistically significant. However, in step 2, Suppression was found to have a positive association with pain severity ratings.

Multiple regression analysis was also used to investigate associations between the PRPQ scales and disability ratings. The analyses were similar to those used regarding pain severity ratings, but pain severity ratings were included as a predictor variable in step 1 along with sex, age and pain duration. Again, there were no statistically significant interaction effects; thus, the final model included only steps 1 and 2. This model is reported as the second analysis in Table 3, and indicates that pain severity ratings and the Solicitude scale had positive associations with disability ratings. The combined set of predictors accounted for $23.6 \%$ of the variance in disability ratings.

Another objective was to investigate the incremental validity of the PRPQ. To this end, the ability of the Suppression scale to account for variance in pain severity ratings beyond that accounted for by the PCS was investigated. The results of this analysis are the first set of findings summarized in Table 4. Age, sex and pain duration were entered in step 1 . The PCS was entered in step 2 and was positively associated with pain severity ratings. The change in the $R^{2}$ value indicated that the addition of the PCS accounted for $6.4 \%$ of the variance in pain severity ratings. The earlier correlation and regression analyses indicated that the Suppression scale was the only PRPQ scale associated with pain severity ratings; therefore, it was the only PRPQ scale entered in step 3. Entering step 3 into the model revealed a small positive association between Suppression and pain severity ratings, which was not statistically significant.

Also related to investigating the incremental validity of the PRPQ, a regression analysis was used to determine whether the PRPQ Solicitude scale could account for unique variance in disability ratings beyond that accounted for by pain catastrophizing. The results of this analysis are the second set of findings summarized in Table 4. Age, sex and pain duration were again entered in step 1. The PCS and Solicitude scale were entered in steps 2 and 3, respectively. Each model was statistically significant. Importantly, the addition of the Solicitude scale in step 3 resulted in a statistically significant improvement to the model. In the final model, pain severity ratings, the PCS and the Solicitude scale all had positive associations with disability
TABLE 4

\begin{tabular}{|c|c|c|c|c|c|}
\hline $\begin{array}{l}\text { Dependent } \\
\text { variable }\end{array}$ & Step & Predictors & $\beta$ & $\mathrm{F}$ & $\Delta \mathbf{R}^{2}$ \\
\hline \multirow[t]{5}{*}{ Pain severity } & 1 & Sex & 0.01 & 1.13 & 0.017 \\
\hline & & Age & -0.10 & & \\
\hline & & Pain duration & 0.06 & & \\
\hline & 2 & $\begin{array}{l}\text { Pain Catastrophizing } \\
\text { Scale }\end{array}$ & $0.23^{* * *}$ & $4.34^{* \star}$ & $0.064^{* \star *}$ \\
\hline & 3 & PRPQ Suppression & 0.12 & $4.04^{* *}$ & 0.012 \\
\hline \multirow{6}{*}{$\begin{array}{c}\text { Disability } \\
\text { ratings }\end{array}$} & 1 & Sex & -0.06 & $12.17^{* * *}$ & $0.199^{* * *}$ \\
\hline & & Age & 0.07 & & \\
\hline & & Pain severity ratings & $0.37^{\star * *}$ & & \\
\hline & & Pain duration & 0.08 & & \\
\hline & 2 & $\begin{array}{l}\text { Pain Catastrophizing } \\
\text { Scale }\end{array}$ & $0.23^{* * *}$ & $13.60^{* \star *}$ & $0.060^{* * *}$ \\
\hline & 3 & PRPQ Solicitude & $0.14^{*}$ & $12.34^{\star \star \star}$ & $0.018^{*}$ \\
\hline
\end{tabular}

Sex coded as male $=0$ and female $=1$. Standardized coefficients reported are from the final models. ${ }^{*} P<0.05$; ${ }^{* *} P<0.01$; ${ }^{* * *} P<0.001$

ratings. The final model accounted for $27.7 \%$ of the variance in disability ratings.

\section{DISCUSSION}

Previous research has supported the construct validity and potential clinical utility of the PRPQ scales $(7,8)$. However, the findings regarding the most appropriate set of scales to use have been inconsistent. Both previous factor analyses of the measure provided empirical support for the Solicitude and Suppression scales. The initial study (7) suggested separate Encouragement and Management scales, whereas the more recent study (8), which involved a sample of tertiary care chronic pain patients, suggested it would be more appropriate to combine these scales into an Activity Direction scale. The first objective of the current study was to evaluate these competing configurations of the PRPQ (ie, three scales versus four scales) and to further refine the measure.

Confirmatory factor analysis indicated that both models tested provided a poor fit to the data. Factor structures are difficult to confirm when testing models based on data from even moderately lengthy questionnaires (20). Given that several of the previously developed PRPQ scales can be considered moderately lengthy (ie, $>8$ items), the current findings are not surprising. Exploratory factor analysis was, therefore, subsequently used to examine the factor structure of the PRPQ and to refine its scales. This process resulted in three scales that had adequate to good levels of internal consistency. The composition of the 10-item Solicitude scale was highly consistent with the versions used in both previous studies of the PRPQ. The Encouragement scale was consistent with the similarly named scale used in the initial psychometric study of the PRPQ, but was comprised of slightly fewer items (five versus seven items). The Suppression scale was also similar to the Suppression scales in previous studies. However, the current version was shorter (three versus six items) and had a higher level of internal consistency (Cronbach's alpha $=0.82$ ) than the versions used in previous studies (Cronbach's alphas $=0.75$ and 0.70 ). As part of developing a more focused Encouragement scale rather than maintaining a broader Activity Direction scale, the items from the original Management scale were omitted from the final Encouragement scale.

Developing a version of the PRPQ that is invariant across a variety of populations is important to allow meaningful cross-group comparisons to be performed. The current scale configuration is based on the findings of two previous factor analyses, as well as the current exploratory factor analysis; thus, it is possible that the scales used in the current study have been refined sufficiently to receive stronger support in 
future confirmatory factor analytical investigations, including those testing its measurement invariance. In addition, the configuration used in the current study used scales with fewer items than the scales used in earlier studies, which should be beneficial in terms of finding support for its measurement invariance.

The second objective of the current study was to determine whether previous findings of associations between the PRPQ scales and disability ratings could be replicated. Previous research (8) revealed no statistically significant correlations between the PRPQ scales and disability ratings. However, in the same study, a multiple regression analysis that included sex, pain severity and each PRPQ scale as predictor variables did reveal associations between each PRPQ scale and disability ratings. Solicitude had a positive association with disability ratings, whereas Activity Direction and Suppression had negative associations with disability. The present study revealed a less complex set of findings. As expected, Solicitude was positively correlated with disability ratings, and this association was also found in the multiple regression analysis that included sex, age, pain duration, pain severity and the other two PRPQ scales. The other PRPQ scales were not associated with disability ratings in either the correlation or regression analyses. There are no clear explanations for the differences in findings across studies. However, it is possible that differences in the PRPQ scales used could have played a role. The current scales are generally shorter (eg, the present five-item Encouragement scale versus the previous 10-item Activity Direction scale) and overlap less (eg, the present maximum shared variance of $7.8 \%$ versus the previous maximum shared variance of $32.5 \%$ ). Thus, the current scales arguably provide more precise assessments of the constructs they were designed to operationalize. Disability was also operationalized differently across studies, which may also have led to the different findings.

Across both studies involving chronic pain patients, the Solicitude scale was positively associated with disability ratings. In light of this consistent finding, it is important for future research to elucidate the process, or processes, underlying this association. Those with an elevated interest in solicitous support may engage in a high level of pain behaviour in an effort to obtain solicitous responses from significant others. This level of pain behaviour could result in increased disability, particularly if it was successful in eliciting solicitous support. Additional research is warranted to determine whether pain behaviour and/or solicitous support mediate the relationship between a desire for solicitous support and disability levels. Given that a relatively large body of research (24-27) indicates that pain patients' perceptions of solicitous support are positively associated with disability, investigating the possibility that this relationship is moderated by support preferences is also warranted. Of course, it also remains possible that disability levels could influence support preferences, with those experiencing more severe disability perceiving a high level of solicitous support as most appropriate for their level of functioning.

The positive association between the Suppression scale and pain severity ratings is another finding unique to the present study. It is possible that the increased reliability of the Suppression scale in the current study facilitated the detection of this association. Several experimental studies $(28,29)$ that manipulated whether participants used suppression when responding to pain from the cold pressor task have demonstrated that suppression results in higher levels of pain intensity. Perhaps individuals who tend to use suppressive coping experience more pain as a result of this strategy and also have a preference for the type of support captured by the Suppression scale because it is consistent with their individual efforts to manage pain.

The PRPQ Encouragement scale was unrelated to either pain severity ratings or disability. These null findings raise the possibility that this scale could be eliminated. However, the Encouragement scale was retained for two reasons. First, previous research (8) found that the closely related Activity Direction scale was negatively associated with disability. Given this previous finding, dropping the Encouragement scale would arguably be premature. Second, the PRPQ was initially developed as a tool for advancing research on the interpersonal context of pain; the Encouragement scale may be useful for this purpose even if it is not particularly useful for predicting clinical outcomes. For example, the present study found a negative relationship between pain duration and the Encouragement scale. The cross-sectional nature of the study limits the conclusions that can be drawn on the basis of this finding. However, this finding does raise the possibility that, over time, individuals with chronic pain become less interested in receiving encouragement to persist with their activities despite pain. The Encouragement scale of the PRPQ could be useful in longitudinal research regarding this possibility.

The final objective of the current study was to investigate the incremental validity of the PRPQ by determining whether its scales could account for unique variance in pain severity and disability beyond that accounted for by the PCS. As expected, the PCS was positively associated with pain severity and disability ratings. The Suppression scale did not account for unique variance in pain severity ratings after including the PCS in the regression model. However, the Solicitude scale was able to account for unique variance in disability ratings after the PCS was entered in the regression model. In light of the large number of pain-related psychological constructs and related self-report measures already developed, this finding is particularly important because it provides some preliminary evidence that the PRPQ assesses a unique component of the pain experience not captured by existing measures.

One unexpected pattern of findings warrants mention. The PCS was positively associated with two PRPQ scales. The Communal Coping Model of pain catastrophizing (10) posits that high pain catastrophizers engage in expressive pain displays that serve a communicative function aimed at maximizing the possibility that pain-related distress will be managed within an interpersonal context. The model does not specify what type of interpersonal support would be desired by those who catastrophize. However, the findings of several studies (30-32) suggest that, at least under some conditions, catastrophizing draws solicitous support from significant others. These studies did not specifically hypothesize that those with elevated levels of catastrophizing have a relatively a strong desire for solicitous pain-related support, but the current finding of a positive correlation between the PCS and the Solicitude scale is consistent with this idea. It is important to note that the PCS was also positively correlated with the Suppression scale. The two correlations involving the PCS and the PRPQ scales could be considered to be contradictory (ie, those high in catastrophizing want attention and the absence of attention). However, the Solicitude and Suppression scales were not correlated with one another, so the finding that pain catastrophizing was positively associated with both these PRPQ scales in not particularly unusual. Rather, this pattern of findings likely provides an accurate indication of the type of interpersonal pain management desired by high pain catastrophizers. They may want others to help them manage their pain and distress by disengaging them from the heightened emotionality associated with the pain (ie, high Suppression) and they may also want expressions of concern and instrumental support in response to their pain (ie, high Solicitude). The current self-report methodology did not allow for an examination of the sequencing of pain-related social support preferences. However, we suspect that high pain catastrophizers may prefer 'calming down' responses to their initial expressive pain displays, and that once their initial distress has been addressed they may be more preoccupied with the view that they need or deserve solicitous support because of their pain.

Several limitations to the findings and methodology of the current study should be noted. The associations between the PRPQ scales and the pain outcomes were not large or consistent because only two of six of these correlations were statistically significant and, in both cases, these were small in magnitude. In addition, the PRPQ Solicitude scale accounted for only $1.8 \%$ of the variance in disability beyond that contributed by pain severity ratings and the PCS. These findings raise the possibility that the relationships observed in the current study involving the PRPQ may be of limited practical importance to clinicians. 
However, it is also important to recognize that the current study only investigated cross-sectional associations among chronic pain patients. It remains possible that the PRPQ may be better suited for predicting the progression of acute pain to chronic pain or for predicting responses to treatment. Research of this nature may provide greater support for the clinical utility of the PRPQ.

In summary, previous factor analytical findings and those of the current study were used to refine the scales of the PRPQ. Items that have had salient cross-loadings were omitted, and a shorter and more focused Encouragement scale was adopted rather than the longer Activity Direction scale used previously (8). This new set of scales has a greater potential to be supported in a confirmatory factor analytical study. Notwithstanding the possibility of further small refinements to

\section{REFERENCES}

1. Fordyce WE. Behavioral Methods for Chronic Pain and Illness. St Louis: The CV Mosby Company, 1976.

2. Romano JM, Jensen MP, Turner JA, et al. Chronic pain patientpartner interactions: Further support for a behavioral model of chronic pain. Behav Ther 2000;31:415-40.

3. Romano JM, Turner JA, Friedman LS, et al. Sequential analysis of chronic pain behaviors and spouse responses. J Consult Clin Psychol 1992;60:777-82.

4. Romano JM, Turner JA, Jensen MP, et al. Chronic pain patientspouse behavioral interactions predict patient disability. Pain 1995;63:353-60.

5. Newton-John TR, Williams AC. Chronic pain couples: Perceived martial interactions and pain behaviours. Pain 2006;123:53-63.

6. Cano A, Williams AC. Social interaction in pain: Reinforcing pain behaviours or building intimacy? Pain 2010;149:9-11.

7. McWilliams LA, Saldanha KM, Dick BD, et al. Development and psychometric evaluation of a new measure of pain-related support preferences: The Pain Response Preference Questionnaire. Pain Res Manag 2009;14:461-9.

8. McWilliams LA, Dick, BD, Bailey K, Verrier MJ, Kowal J. A psychometric evaluation of the Pain Response Preference Questionnaire in a chronic pain patient sample. Health Psychol 2012;31:343-51.

9. Sullivan MJ, Bishop SR, Pivik J. The pain catastrophizing scale: Development and validation. Psychol Assess 1995;7:524-32.

10. Sullivan MJ. The Communal Coping Model of pain catastrophising: Clinical and research implications. Can Psychol 2012;53:32-41.

11. Jensen MP, Turner JA, Romano JM, Fisher LD. Comparative reliability and validity of chronic pain intensity measures. J Pain 1999;83:157-62.

12. International Association for the Study of Pain. Pain Database Questionnaire. Seattle: IAPS, 1995.

13. Kline RB. Principles and Practice of Structural Equation Modeling, 2nd edn. New York: Guildford, 2005.

14. Lei M, Lomax RG. The effects of varying degrees of nonnormality in structural equation modeling. Struct Equ Modeling 2005;12;1-27.

15. Cole DA. Utility of confirmatory factor analysis in test validation research. J Consult Clin Psychol 1987;55:584-94.

16. Jöreskog KG, Sörborn D. LISREL VI: Analysis of Linear Structural Relationships by Maximum Likelihood, Instrumental Variables, and Least Squares Methods. Mooresville, Indiana: Scientific Software, 1986. the measure, the evidence available to date suggests that the PRPQ scales are internally consistent, valid, and related to clinically important variables such as pain and disability. Thus, the PRPQ holds promise as a clinical assessment measure and additional research regarding this possibility is warranted. As well, the PRPQ may be useful for incorporating pain-support preferences into recent interpersonally focused lines of research.

FUNDING AND DISCLOSURES: The present research was supported by a Social Sciences and Humanities Research Council of Canada standard operating grant awarded to Drs McWilliams, Dick and Kowal. The authors have no conflicts of interest to declare.

17. Bentler PM. Comparative fit indices in structural models. Psychol Bull 1990;10:238-46.

18. Fan X, Wang L. Effects of potential confounding factors on fit indices and parameter estimates for true and misspecified SEM models. Educ Psychol Meas 1998;58:699-733.

19. Akaike H. Factor analysis and AIC. Psychometrika 1987;52:317-32.

20. Floyd FJ, Widaman KF. Factor analysis in the development and refinement of clinical assessment instruments. Psychol Assess 1995; 7:286-99.

21. Tabachnik BG, Fidell LS. Using Multivariate Statistics, 5th edn. Toronto: Pearson Education, Inc, 2007.

22. Cohen J. A power primer. Psychol Bull 1992;112:155-9.

23. Aiken LS, West SG. Multiple regression: Testing and interpreting interactions. Thousand Oaks, California: Sage Publications, 1991.

24. Fillingim RB, Doleys DM, Edwards RR, et al. Spousal responses are differentially associated with clinical variables in women and men with chronic pain. Clin J Pain 2003;19:217-24.

25. Flor H, Kerns RD, Turk DC. The role of spouse reinforcement, perceived pain, and activity levels of chronic pain patients. J Psychosom Res 1987;31:251-9.

26. Pence LB, Thorn BE, Jensen MP, et al. Examination of perceived spouse responses to patient well and pain behavior in patients with headache. Clin J Pain 2008;24:654-61.

27. Schwartz L, Jensen MP, Romano JM. The development and psychometric evaluation of an instrument to assess spouse responses to pain and well behavior in patients with chronic pain: The Spouse Response Inventory. J Pain 2005;6:243-52.

28. Cioffi D, Holloway J. Delayed costs of suppressed pain. J Pers Soc Psychol 1993;64:274-82.

29. Masedo AI, Esteve MR. Effects of suppression, acceptance and spontaneous coping on pain tolerance, pain intensity and distress. Beh Res Ther 2006;45:199-209.

30. Buenaver LF, Edwards RR, Haythornthwaite JA. Pain-related catastrophizing and perceived social responses: Inter-relationships in the context of chronic pain. Pain 2007;127:234-42.

31. Cano A. Pain catastrophizing and social support in married individuals with chronic pain: The moderating role of pain duration. Pain 2004;110:656-64.

32. Giardino, ND, Jensen MP, Turner JA, et al. Social environment moderates the association between catastrophizing and pain among persons with a spinal cord injury. Pain 2003;106:19-25. 


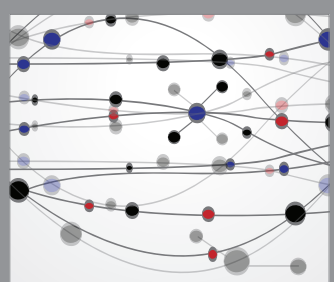

The Scientific World Journal
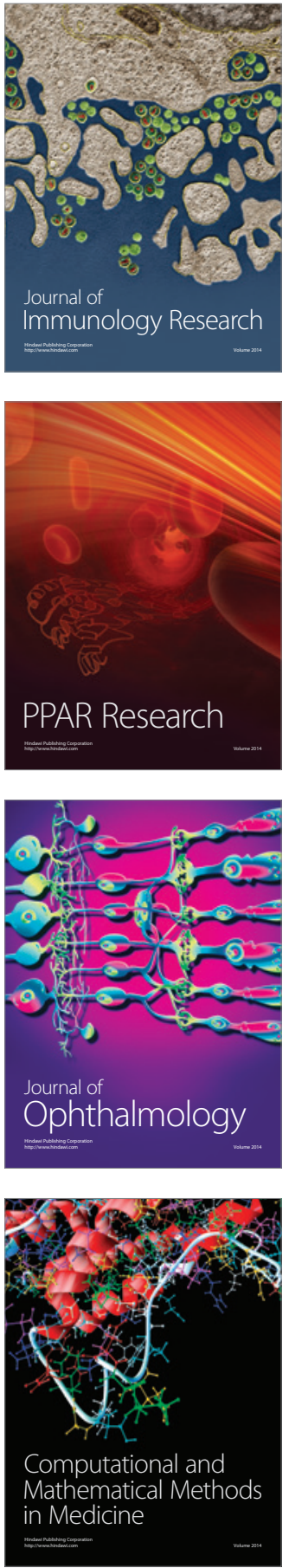

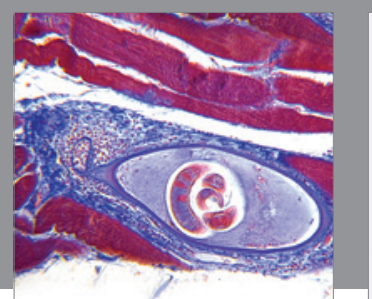

Gastroenterology Research and Practice

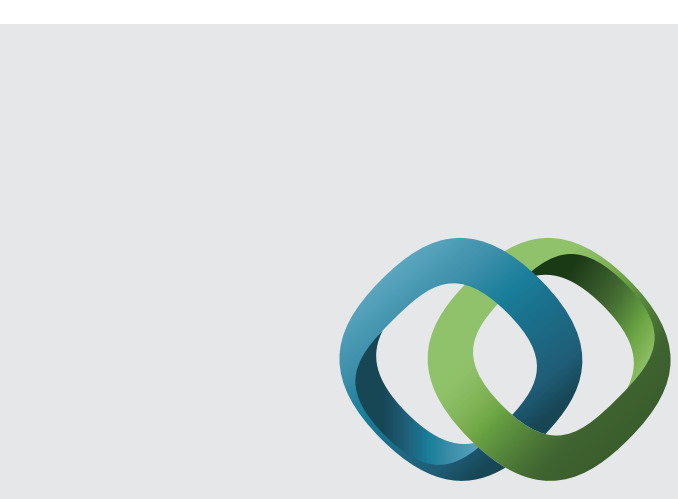

\section{Hindawi}

Submit your manuscripts at

http://www.hindawi.com
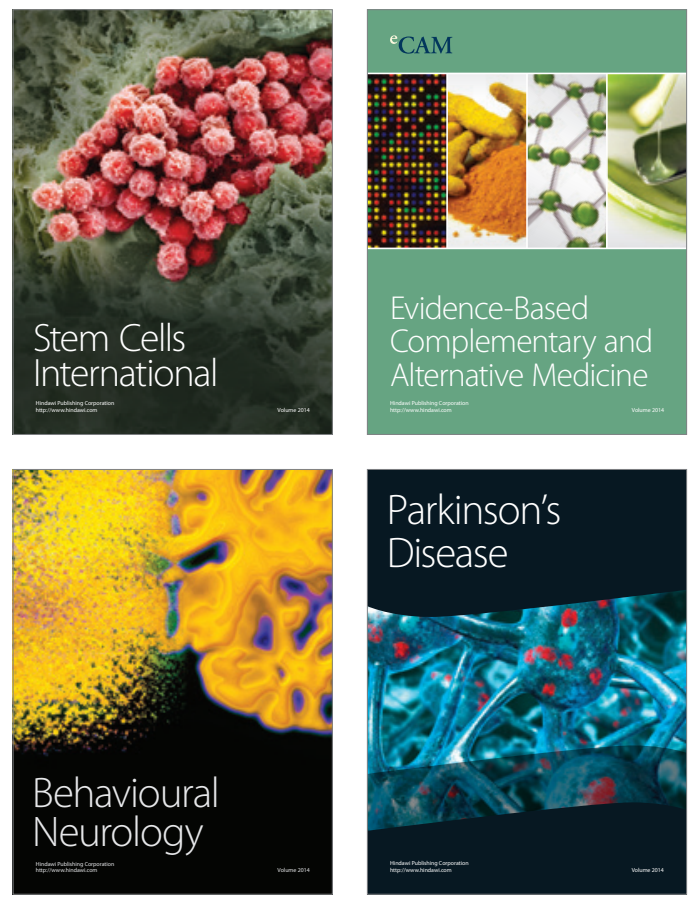
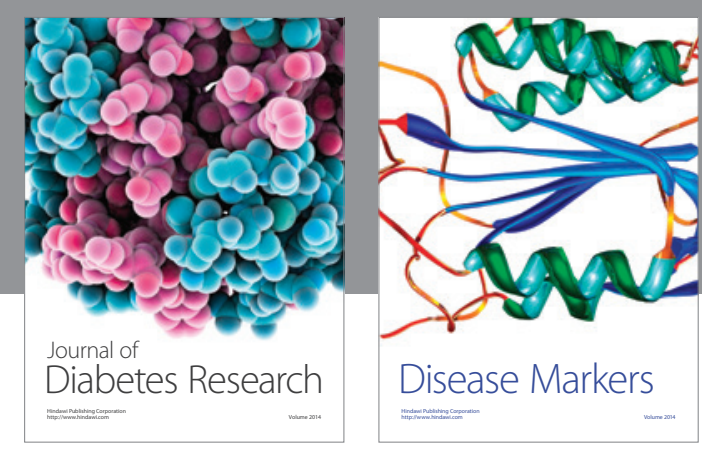

Disease Markers
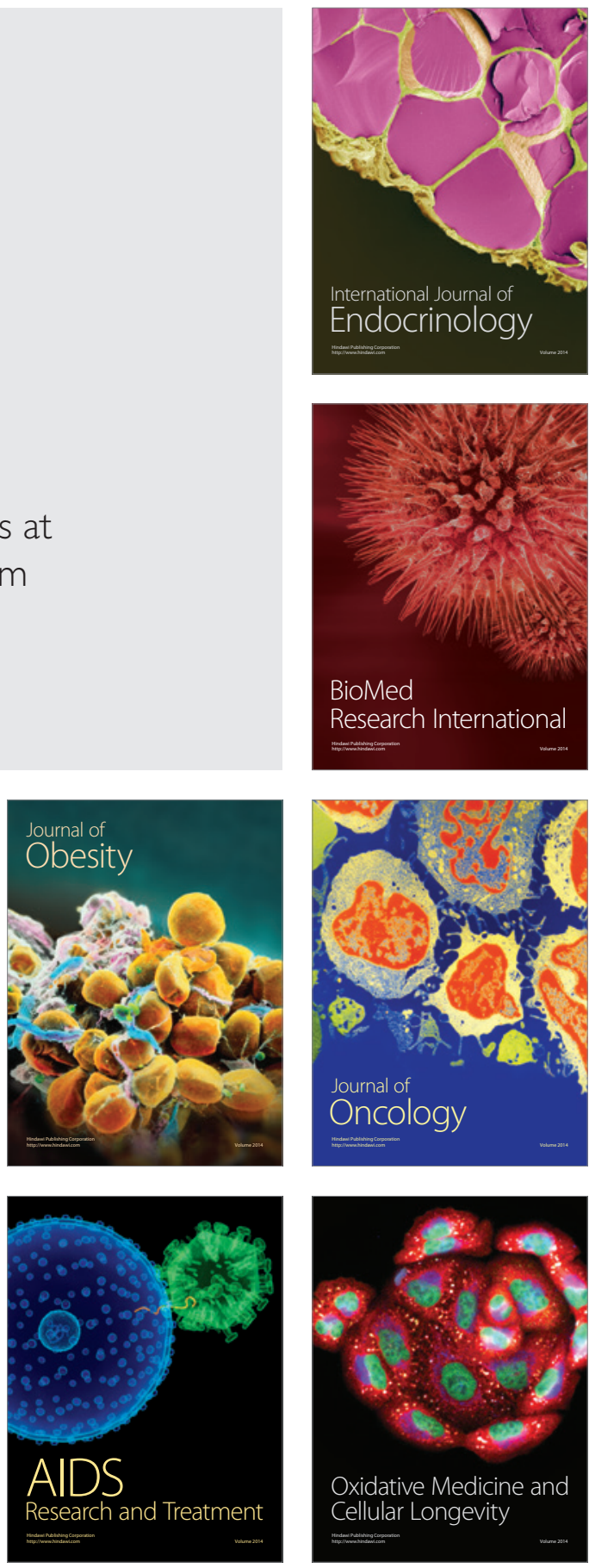